\title{
Deaths from abuse of volatile substances: a national epidemiological study
}

\author{
H R ANDERSON, R S MACNAIR, J D RAMSEY
}

\begin{abstract}
A survey of the United Kingdom detected 282 deaths from abuse of volatile substances during 1971-83. Deaths appeared to have increased in the most recent years, reaching 80 in 1983. Age at death ranged from 11 to 76 years but most deaths $(72 \%)$ occurred under 20 years. Ninety five per cent of the subjects were male, and in 1983 deaths from volatile substance abuse accounted for $2 \%$ of all deaths in males aged 10-19. All areas of the United Kingdom were affected, the rates being highest in Scotland and urban areas. All social classes were affected, though rates were highest in social class $\mathbf{V}$ and the armed forces. The volatile substances abused were gas fuels (24\%), mainly butane; aerosol sprays (17\%); solvents in glues (27\%); and other volatile substances, such as cleaning agents (31\%). In $51 \%$ of cases death was attributed to the direct toxic effects of the substance abused, in $21 \%$ to plastic bag asphyxia, in $18 \%$ to inhalation of stomach contents, and in $11 \%$ to trauma. Deaths associated with the abuse of glues were more likely to be traumatic, but all substances appeared capable of killing directly by their toxic effects, probably by a cardiac mechanism. Only a small proportion of deaths $(6 \%)$ were due to the abuse of glues among children under 16; hence current attempts to limit access of children to glues will probably have little impact on overall mortality.
\end{abstract}

\section{Introduction}

A wide range of volatile substances-mostly halogenated or unsubstituted hydrocarbons-may when inhaled cause changes in mood or consciousness or in some instances hallucinations. The abuse of these substances to get a "high" is commonly though somewhat inaccurately known as "glue sniffing" or "solvent abuse." Deaths associated with abuse of volatile substances tend to receive a lot of publicity, and this has stimulated attempts to introduce various public control measures including education of the general public and professionals, ${ }^{1-4}$ control of supply by legal or voluntary means, ${ }^{5-7}$ and the addition of repellent substances to adhesives. ${ }^{8}$ Manufacturers of relevant products have released a public statement on the subject. ${ }^{9}$

Rational debate and action have been severely hampered by lack of information about the practice and its consequences. We have

St George's Hospital Medical School, London SW17 ORE

H R ANDERSON, MD, FFCM, reader, department of clinical epidemiology and social medicine

R S MACNAIR, SRN, sCM, projects organiser, department of clinical epidemiology and social medicine

J D RAMSEY, head of toxicology unit

Correspondence to: Dr H R Anderson. therefore attempted to detect and investigate all deaths associated with abuse of volatile substances occurring in the United Kingdom over a period of time so that the scale, trends, and nature of the problem may be better appreciated. Preliminary findings in 140 deaths have been reported. ${ }^{10}$ This paper describes the results for 282 deaths occurring between 1971 and 1983.

\section{Methods}

Death associated with abuse of a volatile substance was defined as one caused either directly or indirectly by one of these agents and not occurring at the workplace. The first source of ascertainment was through press clipping agencies employed by three different organisations to scan all newspapers in the United Kingdom for articles containing specified key words relating to the subject. The keywords were "aerosol" (British Aerosol Manufacturers' Association), 6 "glue sniffing" (Institute for the Study of Drug Dependence), and "sniffing deaths" (present authors). The second source of ascertainment was a list of names compiled non-systematically from miscellaneous sources from 1970 to 1980 initially by the Department of Trade and then by the Department of Health and Social Security. The third main source was a règular systematic survey of coroners in England, Wales, and Northern Ireland carried out at six month intervals from 1982. Deaths were also notified to us from the Office of Population Censuses and Surveys. In Scotland we were aided by the Crown Office and the procurators fiscal. After the detection of a death associated.with abuse of a volatile substance the inquest proceedings, postmortem and toxicological findings, and death certificates were obtained.

The strength of evidence connecting the death with abuse of a volatile substance was graded sequentially as: toxicological findings positive for volatile substances; subject witnessed to be sniffing at time of death; circumstantial evidence in a known "sniffer"; and circumstantial evidence without a history of sniffing. Cause of death was classified in such a way as to help distinguish, firstly, those subjects in whum death was almost certainly not directly caused by the volatile substance (for example, trauma); secondly, those in whom the direct role of the volatile substance was questionable (plastic bag found over the head, aspiration of stomach contents); and, thirdly, those in whom the only explanation for the death was that it had been a consequence of the direct toxic effects of the volatile substance itself.

Statistical significance was calculated by $\chi^{2}$ test. Confidence intervals for standardised mortality ratios were calculated by two methods: if the observed number of deaths was 30 or less a table of the exact confidence interval for the mean of a Poisson variable was used ${ }^{11}$; when the observed number was greater than 30 the standard error formula $\sqrt{\mathrm{O} / \mathrm{E}}$ was used (where $\mathrm{O}$ and $\mathrm{E}$ represent observed and expected numbers of deaths, respectively)

\section{Results}

During 1971-83 the number of deaths detected increased year by year, reaching 80 in 1983 (table I). The increase was found by each method of ascertainment-including the period 1981-3, when methods were applied prospectively. In most cases $(80 \%)$ there was some mention of volatile substances on the death certificate, though not necessarily among the stated causes of death.

The following data were obtained for the deaths: inquest proceedings 
TABLE I-Deaths associated with volatile substance abuse 1971-83: numbers, sources of ascertainment, and mention of volatile substance on death certificate

定

\begin{tabular}{|c|c|c|c|c|c|c|c|c|c|c|c|c|c|c|}
\hline & \multicolumn{13}{|c|}{ Year } & \multirow{2}{*}{ Total } \\
\hline & 71 & 72 & 73. & 74 & 75 & 76 & 77 & 78 & 79 & 80 & 81 & 82 & 83 & \\
\hline No of deaths & 2 & 4 & 3 & 2 & 9 & 7 & 7 & 14 & 20 & 29 & 45 & 60 & 80 & 282 \\
\hline $\begin{array}{l}\text { Source of ascertainment: } \\
\text { Press clipping (key word “aerosol”) (since 1970) }\end{array}$ & & & 2 & 1 & 4 & 2 & 4 & 3 & 5 & 10 & 8 & 6 & 9 & 54 \\
\hline Press clipping (key words “glue sniffing”) (since 1976) & & & & & 2 & 3 & 1 & 4 & 2 & 18 & 23 & 28 & 54 & 135 \\
\hline Press clipping (key words "sniffing death") (since 1981) & & 1 & & & & & 1 & 1 & 2 & 14 & 39 & 39 & 65 & 162 \\
\hline Coroner's survey, Scottish Crown Office (since 1982) & & & & & & & & 1 & 7 & 7 & 3 & 31 & 45 & 94 \\
\hline Departments of Trade and Health (ceased 1980) & 2 & 4 & 3 & 2 & 6 & 6 & 3 & 7 & 9 & 2 & & & & 44 \\
\hline Death certificate obtained (No with mention of solvents) & $2(0)$ & $3(0)$ & $3(0)$ & $2(0)$ & $8(0)$ & $7(6)$ & $7(6)$ & $13(11)$ & $17(15)$ & $27(22)$ & $45(32)$ & $59(52)$ & $65 *(64)$ & $258(208)$ \\
\hline
\end{tabular}

*Some outstanding due to normal delay.

( $73 \%$ of cases); necropsy results (94\%); toxicological findings (67\%); death certificates $(93 \%)$; press clippings $(62 \%)$; other material-for example, letters from coroners- $(30 \%)$. The strength of evidence connecting a volatile substance with the death was, in decreasing level of certainty: toxicological findings positive for volatile substances (67\% of cases); witnessed to be sniffing at time of death (6\%); circumstantial in a known sniffer $(8 \%)$; circumstantial only $(14 \%)$; not known $(4 \%)$.

The figure gives the age distribution of the subjects at death. The median age at death was 17 years, with a range of 11-76 years. Forty four subjects $(16 \%)$ were under the age of 15 , and $201(71 \%)$ were under 20 . Most $(95 \%)$ were male. Analysis by the time periods 1971-80, 1981-2, and 1983 showed no evidence of a trend in age distribution. There was no significant association between age distribution and the method of ascertainment.

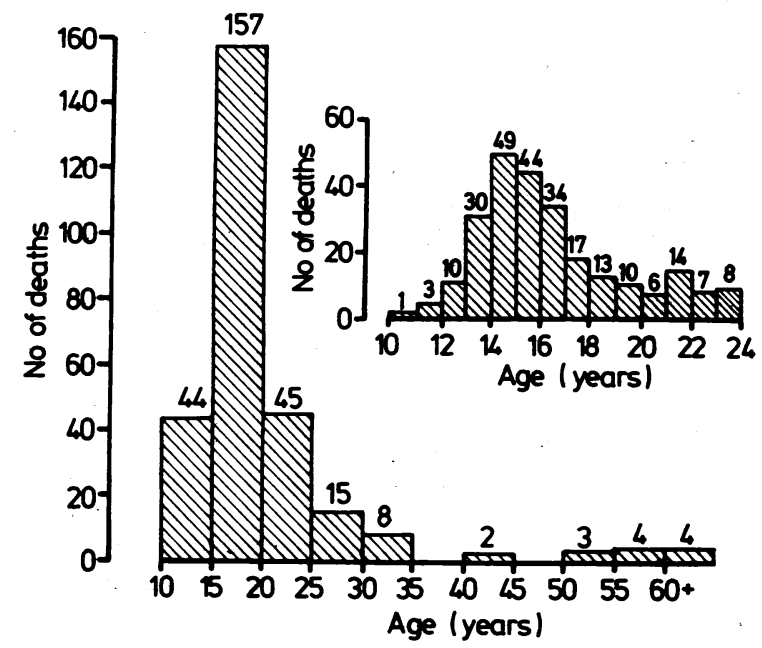

Age distribution in deaths associated with volatile substance abuse in United Kingdom, 1971-83.

Using the total for 1982 as the denominator, abuse of volatile substances in 1983 in Great Britain was estimated to account for $1.5 \%$ of all deaths in boys aged $10-14,2 \cdot 4 \%$ in youths aged $15-19$, and $0.6 \%$ in men aged $20-24$. As a proportion of deaths due to injury and poisoning the respective figures were $3 \cdot 2 \%, 3 \cdot 4 \%$, and $0 \cdot 9 \%$.

Table II shows the geographical distribution of the deaths. There was a highly significant variation in standardised mortality ratios among the countries of the United Kingdom, with the highest in Scotland (178) and the lowest in Wales (80). Within England the variations were more difficult to interpret because of the random variation associated with small numbers. There was, however, no evidence of a north-south gradient. The possible effects of environment were examined by comparing the standardised mortality ratios of the types of county within England. This showed a significant association, the standardised mortality ratio being highest in London (132), intermediate in metropolitan counties (102), and lowest in non-metropolitan counties (80). There was no evidence of a shift in the regional distribution of deaths over time; there was, however, a highly significant trend towards younger deaths in the north $\left(\chi^{2}\right.$ test for trend 10.3 ; p $<0.01$ ).

The distribution of deaths by social class was significantly different from that described for the whole population at the 1981 Census, ${ }^{12} 13$ being more common than expected in social class V and the armed forces (table III); nevertheless, all social classes were well represented, and the overall impression was that the association with social class was only modest. Of subjects aged under $18,10 \%$ (17) were in care compared with an expected $0.8 \% .^{14}$ Of those aged 18 or more $72 \%$ were unmarried and $67 \%$ were employed or students.

Deaths were most likely to occur at home, usually in the bedroom (118 cases; $42 \%)$, or in a public place $(81 ; 29 \%)$. A further 30 subjects ( $11 \%)$ died in hospital, though some of these were almost certainly dead on arrival. There was no significant association between deaths from abuse of volatile substances and month of the year. There was, however, a significant association with the day of the week $(p<0.01)$, Saturday showing the highest number and Thursday the lowest.

In most cases $(71 \%)$ the victim had been sniffing while alone. In $17(8 \%)$ of those for whom inquest data were available there was evidence that the inhalation of solvents was associated with autoerotic behaviour. Among this group constriction of the neck with or without a plastic bag over the head was observed in six cases and some form of bondage in four. The most common verdict was misadventure (63\%), followed by accident $(27 \%)$, open verdict $(4 \%)$, and suicide $(5 \%)$. There was no overall association between verdict and age, though there was a significant trend away from a verdict of misadventure towards an open or suicide verdict with increasing age $\left(\chi^{2}\right.$ for trend $5.84 ; p<0.01$ ).

The commercial product was not always recorded. When more than one substance was involved we usually accepted the coroner's opinion on which was the most important. Table IV lists the main substances implicated in the

TABLE II-Deaths associated with volatile substance abuse 1971-83, by country and English region

\begin{tabular}{lcccc}
\hline Country/region & $\begin{array}{c}\text { No of } \\
\text { deaths }\end{array}$ & Expected & $\begin{array}{c}\text { Age standardised } \\
\text { mortality ratio }\end{array}$ & $\begin{array}{c}95 \% \text { confidence } \\
\text { interval }\end{array}$ \\
\hline Scotland & 48 & $27 \cdot 0$ & 178 & $127-228$ \\
Wales & 11 & $13 \cdot 8$ & 80 & $40-143$ \\
Northern Ireland & 7 & $8 \cdot 4$ & 83 & $33-172$ \\
England & 216 & $232 \cdot 7$ & 92 & $80-105$ \\
Northern & 16 & $15 \cdot 9$ & 101 & $58-163$ \\
North West & 38 & $33 \cdot 3$ & 114 & $78-150$ \\
Yorkshire and Humberside & 21 & $24 \cdot 7$ & 85 & $53-130$ \\
East Midlands & 13 & $19 \cdot 2$ & 68 & $36-116$ \\
West Midlands & 20 & $26 \cdot 5$ & 76 & 46.117 \\
East Anglia & 3 & $9 \cdot 0$ & 33 & $7-97$ \\
South East & 91 & $83 \cdot 3$ & 109 & $87-132$ \\
South West & 14 & $20 \cdot 8$ & 67 & $37-113$ \\
London & 44 & $33 \cdot 31$ & 132 & $93-171$ \\
Metropolitan counties & 60 & $58 \cdot 64$ & 102 & $76-128$ \\
Non-metropolitan counties & 112 & $140 \cdot 80$ & 80 & $65-94$ \\
\hline
\end{tabular}

Testing null hypothesis of no difference between countries: $\chi^{2}=18 \cdot 3 ; 3 \mathrm{df} ; \mathrm{p}<0.001$ Testing null hypothesis of no difference between types of county within England: $\chi^{2}=8.78 ; 2 \mathrm{df}$;
p $<0.05$.

TABLE III-Deaths associated with volatile substance abuse, by social class ${ }^{\star}$

\begin{tabular}{|c|c|c|c|c|}
\hline Social class & $\begin{array}{c}\begin{array}{c}\text { Age }<16 \text { years } \\
\text { (head of } \\
\text { household's } \\
\text { occupation) }\end{array} \\
\text { No \% }\end{array}$ & 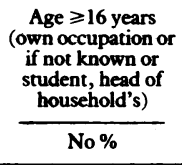 & $\frac{\text { Totalt }}{\text { No } \%}$ & $\begin{array}{c}\begin{array}{c}\text { Census } 1981 \\
\text { (head of household) } \\
\%\end{array} \\
\end{array}$ \\
\hline $\begin{array}{l}\text { I } \\
\text { II } \\
\text { III } \quad\left\{\begin{array}{l}\text { Non-manual } \\
\text { Manual }\end{array}\right. \\
\text { IV } \\
\text { V } \\
\text { Armed forces }\end{array}$ & $\begin{array}{rr}4 & 5 \\
11 & 15 \\
6 & 11 \\
27 & 36 \\
17 & 23 \\
9 & 12 \\
1 & 1\end{array}$ & $\begin{array}{rr}9 & 5 \\
26 & 15 \\
15 & 9 \\
45 & 26 \\
31 & 18 \\
30 & 17 \\
16 & 9\end{array}$ & $\begin{array}{rr}13 & 5 \\
37 & 15 \\
21 & 9 \\
72 & 29 \\
48 & 19 \\
39 & 16 \\
17 & 7\end{array}$ & $\begin{array}{r}6 \\
24 \\
12 \\
34 \\
16 \\
5 \\
3\end{array}$ \\
\hline Total & 75100 & 172100 & 247100 & 100 \\
\hline
\end{tabular}

*Insufficient information on 35 deaths.

tGoodness of fit using 1981 Census to estimate expected deaths: $x_{6}^{2}=77 \cdot 4 ; p<0.001$ 
deaths. Solvents in glues were associated with just over a quarter of deaths. None of this group had any mention of a substance from one of the other groups. Eight different brands were mentioned, the most frequent being Evostik (74\%). Of the 52 cases with a toxicological report, 42 showed evidence of toluene, followed by trichloroethylene (3), hexane (3), 1,1,1-trichloroethane (2), tetrachloroethylene (1), and methyl ethyl ketone (1).

TABLE IV-Volatile substances abused, by product and age

\begin{tabular}{|c|c|c|c|c|c|}
\hline \multirow{2}{*}{ Product } & \multicolumn{4}{|c|}{ Age (years) } & \multirow{2}{*}{ Total (\%) } \\
\hline & $<16$ & $16-17$ & $18-24^{\star}$ & $\geqslant 25$ & \\
\hline $\begin{array}{l}\text { Lighter fuel } \\
\text { Other products } \\
\text { Not known }\end{array}$ & $\begin{array}{r}19 \\
1 \\
7\end{array}$ & $\begin{array}{c}\text { fuels } \\
16 \\
0 \\
2\end{array}$ & $\begin{array}{r}11 \\
4 \\
3\end{array}$ & $\begin{array}{l}1 \\
3 \\
1\end{array}$ & $\begin{array}{r}47 \\
8 \\
13\end{array}$ \\
\hline Total No of deaths & 27 & 18 & 18 & 5 & 68 (24) \\
\hline $\begin{array}{l}\text { PR Spray } \\
\text { Fire extinguisher } \\
\text { Antiperspirant } \\
\text { Air freshener } \\
\text { Cleaners } \\
\text { Fly spray } \\
\text { Paint spray } \\
\text { Hair spray } \\
\text { Not known }\end{array}$ & $\begin{array}{l}5 \\
5 \\
5 \\
1 \\
1 \\
1 \\
= \\
=\end{array}$ & $\begin{array}{c}\text { spray } \\
7 \\
4 \\
1 \\
1 \\
= \\
\frac{1}{-}\end{array}$ & $\begin{array}{l}\frac{3}{1} \\
\frac{1}{1} \\
\frac{3}{1}\end{array}$ & $\begin{array}{l}\frac{2}{7} \\
\frac{1}{1} \\
\frac{1}{2}\end{array}$ & $\begin{array}{r}17 \\
10 \\
6 \\
4 \\
4 \\
2 \\
4 \\
1 \\
1\end{array}$ \\
\hline Total No of deaths & 18 & 14 & 11 & 6 & $49(17)$ \\
\hline $\begin{array}{l}\text { Named brand with toluene } \\
\text { Glue (with toluene) } \\
\text { Glue (non-toluene) } \\
\text { Not known }\end{array}$ & $\begin{array}{r}12 \\
2 \\
2 \\
2\end{array}$ & $\begin{array}{c}20 \\
\frac{3}{3} g h \\
\frac{3}{3}\end{array}$ & $\begin{array}{r}13 \\
-5 \\
4 \\
2\end{array}$ & $\frac{6}{2}$ & $\begin{array}{c}51 \\
12 \\
6 \\
8\end{array}$ \\
\hline Total No of deaths & 18 & 26 & 24 & 9 & 77 (27) \\
\hline $\begin{array}{l}\text { Cleaning agents } \\
\text { Plaster remover } \\
\text { Correcting fluid thinner } \\
\text { Glitter lamp fluid } \\
\text { Chloroform } \\
\text { Petrol } \\
\text { Paint thinner } \\
\text { Other } \\
\text { Not known }\end{array}$ & $\begin{array}{l}O v i \\
9 \\
6 \\
5 \\
3 \\
1 \\
1 \\
\frac{1}{5}\end{array}$ & $\begin{array}{c}\text { ile subs } \\
4 \\
5 \\
5 \\
\frac{5}{1} \\
\frac{1}{4}\end{array}$ & $\begin{array}{l}8 \\
\frac{5}{7} \\
\frac{1}{2} \\
2 \\
3\end{array}$ & $\begin{array}{l}\frac{7}{7} \\
\frac{3}{3} \\
\frac{1}{5}\end{array}$ & $\begin{array}{r}28 \\
16 \\
10 \\
3 \\
5 \\
2 \\
3 \\
3 \\
17\end{array}$ \\
\hline Total No of deaths & 30 & 20 & 21 & 16 & $87(31)$ \\
\hline Grand total No of deaths & 93 & 78 & 74 & 36 & $281(100)$ \\
\hline
\end{tabular}

*One solvent not known in 18-24 year age group.

Other volatile substances were implicated in $31 \%$ of deaths and included at least $\mathbf{2 0}$ different products. Two cases in this group had mention of a substance from another group (butane, 1; aerosol spray, 1). Toxicological analysis in 79 cases in the group detected 16 different volatile substances, the most frequent being 1,1,1-trichloroethane ( 42 cases), followed by trichloroethylene (10), chloroform (7), carbon tetrachloride (5), and toluene (4).

One quarter of deaths were associated with the abuse of gas fuels containing the alkane gas butane or, less commonly, propane. Gas cigarette lighter fillers accounted for $80 \%$ of this group.

Aerosols were the least common category (17\%). These usually contain halocarbon propellants 11 or 12 , but may include some butane. ${ }^{15}$ Other groups mentioned in the aerosol group were solvents in glue (two cases), gas fuels (two), and in two cases the aerosol delivered a solvent. At least 13 products were incriminated but the most common was PR (pain relief) Spray, followed by fire extinguishing agents containing bromochlorodiffuoromethane.

Non-volatile potentially harmful or contributory substances were occasionally detected toxicologically. The most common were alcohol (24 cases), followed by barbiturates (4), amitriptyline (1), and benzamphetamine (1). These were not significantly associated with the category of volatile substance.

There was no significant association between the category of volatile substance and the verdict or the strength of evidence connecting the substance with death. The relative importance of each category of volatile substance did not change significantly over time, nor were there any associations with age or with country or region.

Table $\mathrm{V}$ analyses the different mechanisms or causes of death by broad category of substance. Trauma accounted for 31 of deaths (11\%), of which 11 were due to drowning, nine to hanging, and 11 to multiple or head injuries. Traumatic deaths accounted for a much higher proportion of deaths associated with glue than with other substances. In the 58 subjects $(21 \%)$ who were found with a plastic bag over the head and the $50(18 \%)$ who
TABLE V-Mechanism of death, by substance

\begin{tabular}{|c|c|c|c|c|c|}
\hline \multirow{3}{*}{$\begin{array}{l}\text { Mechanism } \\
\text { of death }\end{array}$} & \multicolumn{4}{|c|}{ Substance } & \multirow[b]{2}{*}{ Total } \\
\hline & $\begin{array}{c}\text { Gas } \\
\text { fuels* }\end{array}$ & $\begin{array}{l}\text { Aerosol } \\
\text { sprays }\end{array}$ & $\begin{array}{l}\text { Solvents } \\
\text { in glues }\end{array}$ & $\begin{array}{l}\text { Other volatile } \\
\text { substances }\end{array}$ & \\
\hline & No $\%$ & No $\%$ & No $\%$ & No $\%$ & No $\%$ \\
\hline $\begin{array}{l}\text { Traumat } \\
\text { Plastic bag over head } \\
\text { Inhalation of stomaach contents } \\
\text { Direct toxic effects of substance }\end{array}$ & $\begin{array}{rr}0 & \\
15 & 22 \\
15 & 22 \\
37 & 55\end{array}$ & $\begin{array}{rr}1 & 2 \\
10 & 20 \\
10 & 20 \\
28 & 57\end{array}$ & $\begin{array}{rr}29 & 38 \\
21 & 27 \\
4 & 5 \\
23 & 30\end{array}$ & $\begin{array}{rr}0 & \\
12 & 14 \\
21 & 24 \\
54 & 62\end{array}$ & $\begin{array}{rr}30 & 11 \\
58 & 21 \\
50 & 18 \\
142 & 51\end{array}$ \\
\hline All mechanisms & 67100 & 49100 & 77100 & 87100 & 280100 \\
\hline
\end{tabular}

*In one death cause not known.

+ In one death subst.
$\chi_{9}^{2}=95 \cdot 1 ; p<0 \cdot 001$.

showed evidence of inhaled stomach contents it was not certain whether death occurred for these reasons or was caused primarily by direct toxic effects. There remained 142 deaths $(51 \%)$ which could be assumed to have resulted directly from the toxic effects of the substance itself.

There was no evidence of a change in the relative distribution of causes of death over time, nor was there an association with country or region of death. There was evidence of a trend towards plastic bag associated deaths with increasing age, but this failed to reach significance $\left(\chi^{2}=3 \cdot 36 ; p=0.07\right)$.

\section{Discussion}

Concern about mortality from abuse of volatile substances began in the 1960 s in the United States, and fragmentary evidenceprincipally that of Bass ${ }^{16}$ - suggested that mortality increased during that time. An increase was also reported from Sweden, ${ }^{17}$ but in contrast there appeared to have been no increase in Denmark. ${ }^{18}$ The first substantial report on deaths in Britain was by Watson, who showed in her analysis of 45 deaths a doubling between 1970-3 and $1974-5 .{ }^{19}$ With the addition of one study from Japan, ${ }^{20}$ these reports are the only epidemiological data available on the problem, and none are of the size of our series.

The ascertainment of deaths associated with abuse of volatile substances depends on suspecting the possibility of a connection with these substances, on carrying out the necessary toxicological investigations, and on recording the connection with solvents on the death certificate. These processes are susceptible to fashion and individual variation, and in the case of press cuttings the degree of interest by the media is also important. Since each of our methods of ascertainment disclosed an increase, however, probably at least part of the observed trend represents a real increase in mortality. This applies with more certainty from 1981 to 1983, during which data were collected prospectively. Whatever the trend may be, our results suggest that among adolescent males abuse of volatile substances currently accounts for $2 \%$ of deaths from all causes and for over $3 \%$ of deaths from accidents, poisoning, and violence. This places abuse of volatile substances among the leading causes of death for this group of the population.

Most debate on the problem has focused on the adolescent group. It is therefore important to note that nearly $30 \%$ of deaths were in subjects aged 20 or more. It is also widely supposed that these deaths occur in disadvantaged people living in deprived areas. The findings in relation to social class and urban-rural differences provide some support for this, which is strengthened by the finding that among those under 18 the number in local authority care was over 10 times that expected from national figures. Our preliminary investigations into the effects of environment using a classification of residential neighbourhoods (ACORN) based on the 1981 Census $^{21}$ found the highest mortality to be in areas typified as "council estates with worst poverty."

One public control measure proposed is to restrict the access of children under 16 to glues by voluntary or legal means..$^{5-7}$ Another is to compel manufacturers to add repellent substances to their products to deter deliberate inhalation. ${ }^{8}$ Our results indicate that the effects of such measures (assuming that they did in fact reduce the abuse of glue) are likely to be less than might be hoped, since this substance accounted for only one fifth (18/93) of deaths in the under $16 \mathrm{~s}$, which in turn accounted for only $33 \%$ of all deaths (table IV). 
Arguably restrictions on access to glue products might make matters worse if, instead of preventing abuse, they induced a switch to other accessible but more dangerous products. This leads to the controversial question whether risk varies with the type of substance abused. This is a complex issue and requires consideration of three interrelated factors: $(a)$ whether death is due directly to the toxic effects of the substance itself, a result of the method of abuse (for example, a plastic bag), or a consequence of the intoxication (for example, trauma, inhalation of stomach contents while unconscious); (b) control by the abuser over the amount inhaled; and (c) the chemical nature of the substance itself. On the basis of our mortality data we cannot estimate risk in relation to different substances because we lack data on the prevalence of their abuse. While the role of trauma was relatively greater among glue deaths, it must also be noted that $23(30 \%)$ of the deaths associated with glue appeared to be due to its direct toxic effects. Some of these deaths were associated with second substances, and in others the details of death were not sufficient to be completely certain that the solvent in the glue was responsible. The same argument applies, however, to deaths associated with other groups of volatile substance. On present evidence we must conclude that whether or not there are variations in risk according to the substance abused, none are safe.

Various mechanisms have been postulated on how these substances cause death. ${ }^{22-26}$ The most favoured theory is that death is due to cardiac arrhythmia, and evidence in animals ${ }^{27-30}$ and $\operatorname{man}^{30} 31$ supports this. Bass suggested that these volatile substances sensitise the heart to the effects of sympathetic stimulation which may occur during sudden exercise and other activities. ${ }^{16}$ It is relevant that in some deaths there was evidence of autoerotic activity, which has been noted in deaths from abuse of volatile substance ${ }^{32}{ }^{33}$ and which would cause sympathetic stimulation. Some of these deaths fit the description of "sexual asphyxia." We found it very difficult to obtain useful information from the postmortem reports, whose conclusions frequently appeared to reflect the supposed mechanism rather than being based on the primary evidence of the necropsy itself.

We thank the Institute for the Study of Drug Dependence and the British Aerosol Manufacturers' Association for giving us access to their press cuttings; the Scottish Crown Office for information on Scottish deaths; the medical statistics unit of the Office of Population Censuses and Surveys for supplying the death certificates; and the coroners who notified cases to us. Financial support for the data collection was received from the Department of Health and Social Security.

\section{References}

1 Guy's Hospital. Symposium on solvent abuse, November 1981. Hum Toxicol 1982;1:201-353. 2 Institute for the Study of Drug Dependence. Teaching about a volatile substance. London: ISDD, 1980.

3 Central Office of Information. Illusions. London: COI, 1983. (Films/videotape.)

4 Department of Health and Social Security. New measures to combat glue sriffing. London: DHSS, 1983. (Press release.)

5 Patten J. Parliamentary written answer. Voluntary restraints on sales of solvent based products. House of Commons Official Report (Hansard) 1983 December 15

6 Akerman HE. The constitution of adhesives, and its relationship to solvent abuse. Hum Toxicol 1982;1:223-30.

7 House of Commons. Limitation of sales of solvents. London: HMSO, 1984. (Bill 172.)

8 House of Commons. Glue abuse (prevention). London: HMSO, 1984. (Bill 165.)

9 British Adhesives and Sealants Association. Solvent abuse. Information from the adhesive manufacturers. Staffordshire: BASA, 1984

10 Anderson HR, Dick B, Macnair RS, Palmer JC, Ramsey JD. An investigation of 140 deaths associated with volatile substance abuse in the United Kingdom (1971-1981). Hum Toxicol 1982;1:207-21.

11 Pearson ES, Hartley HO. Biometrika tables for statisticians. 3rd ed. Vol 1. Cambridge: Cambridge University Press, 1970.

12 Office of Population Censuses and Surveys. Classification of accupations 1980. London: HMSO, 1980.

13 Office of Population Censuses and Surveys. Census 1981. National report. Great Britain. Part 1. London: HMSO, 1983.

14 Central Statistical Office. Regional trends. London: HMSO, 1984: 32-3.

15 Roberts DJ. Abuse of aerosol products by inhalation. Hum Toxicol 1982;1:231-8.

16 Bass M. Sudden sniffing death. FAMA 1970;212:2075-9.

17 Edh M. Selerud A, Sioberg C. Death and sniffing. A report on 63 cases. Lakartidningen 1973;70: Edh M, Selerud A, Sjoberg C. Death and

18 Kringsholm B. Sniffing-associated deaths in Denmark. Forensic Sci Int 1980;15:215-25.

19 Watson JM. Morbidity and mortality statistics on solvent abuse. Med Sci Law 1979;19:246-52.

20 Nomiyama K, Nomiyama H. Epidemiology of thinner sniffing. Nippon Eiseigaku Zasshi 1969;24: 454-8.

21 CACI Market Analysis Group. ACORN: a new approach to market analysis. London: CACI.

22 Hall FB, Hine CH. Trichloroethane intoxication: a report of two cases. I Forensic Sci 1966;11: 40413 .

$23 \mathrm{Haq} \mathrm{MZ}$, Hameli AZ. A death involving asphyxiation from propane inhalation. $\mathcal{J}$ Forensic $S c i$ 1980;25:25-8.

24 Baselt RC, Cravey RH. A fatal case involving trichloromonofluromethane and dichlorodifluoromethane. I Forensic Sci 1968;13:407-10.

25 Fagan DG, Forrest JB. "Sudden sniffing death" after inhalation of domestic lipid-aerosol. Lancet 1977;ii:361.

Cohen S. The volatile solvents. Public Healeh Reo 1973;11:185-214.

27 Taylor GJ, Harris WS. Cardiac toxicity of aerosol propellants. JAMA 1970;214:81-5.

27 Taylor GJ, Harris WS. Cardiac toxicity of aerosol propellants. JAMA 1970;214:81-5.
28 Reinhardt CF, Azar A, Maxfield ME, Smith PE, Mullin LS. Cardiac arrhythmias and aerosol "sniffing." Arch Enoiron Health 1971;22:265-79.

. TAMA 1972:219:33-7.

30 Mullin LS, Azar A, Reinhardt CF, Smith PE, Fabryka EF. Halogenated hydrocarbon-induced cardiac arrhythmias associated with release of endogenous epinephrine. Am Ind Hyg Assoc $\mathcal{J}$ 1972;33:389-96.

31 Kamm RC. Fatal arrhythmia following deodorant inhalation. Forensic Science 1975;5:91-3.

32 Poklis A. Sudden sniffing death. Can Med Assoc $\mathcal{F}$ 1976;115:208.

33 Cordner SM. An unusual case of sudden death associated with masturbation. Med Sci Law 1983;23:54-6.

34 Camps F, ed. The sexual asphyxias. In: Gradwooh's legal medicine. 2nd ed. Bristol: John Wright, 1968:549-52.

(Accepred 16 November 1984)

\section{MATERIA NON MEDICA}

\section{The stroke}

My father was 70, and semiretired from general practice in London, when he had a massive stroke. He was admitted to the local general hospital. Hemiplegic and totally aphasic, he looked about him as though lost, and cried when he was visited by my mother or by his brother, a few years his junior.

I visited him alone daily and chatted about the world in general; about family affairs; about the not very successful attempts of the physical therapist to work on his limbs. He would look at me, moving his eyes and unilateral expressive facial musculature in ways that told me at least something of what he was thinking. I took him some newspapers, which he looked at without interest, and then some picture magazines, which seemed to awaken somewhat more enthusiasm. He leafed the pages with his good hand, glanced at the pictures, and often turned the magazine upside down. The weeks turned to months and I realised that his time with us was drawing to a close.

One day I added a fresh copy of the $B M F$ to the picture magazines. The journal in its blue cover had been read by him for the previous 40 years-some sections more avidly than others. As he became aware of its presence he became obviously very excited. He pushed the other papers aside and, with difficulty and yet with fortitude, turned the pages of the $B M$ J. Slowly and methodically he went through them, looking carefully, it seemed, almost as though he were trying to capture all the latest medical news, research, and treatments.

And then he found it-the section that he had obviously been searching

for. With precision he gently but firmly folded back the page and handed me the journal. He looked deeply into my eyes and I am sure that I read a touch of a smile on his face. It was the obituary section, the $B M \mathcal{F}$ always carrying personal notes that, in a paragraph or two, allow a succinct closure to the professional life of our colleague of yesterday. I knew that he was asking me to write his obituary and telling me that I was not to make it too heavy.

Two weeks later my father died. I think he would have approved of his obituary.-GODFREY D RIPLEY, associate professor, Texas, USA.

I recall reading that leoodopa (Madopar) should be carefully administered in patients with osteoporosis. Why is this?

The manufacturer's data sheet for Madopar (levodopa and benserazide) states that it should be used with caution in patients with osteoporosis. There are two reasons for this warning: firstly, the increased mobility produced by effective treatment might increase the risk of falls and therefore fractures in patients with osteoporosis and, secondly, high doses of benserazide ( 20 times the maximum recommended therapeutic dose) have been associated with severe bone deformities in rats. There is no evidence in man to support this warning, and the company proposes to remove the reference to osteoporosis when the data sheet is next reprinted (Roche Products Ltd, personal communication). - LINDA BEELEY, consultant clinical pharmacologist, Birmingham. 